\title{
Vivência do cuidador familiar de homem com traqueostomia por câncer
}

\author{
Family caregiver's experience of a man withttracheostomy due to cancer \\ Vivencia del cuidador familiar de hombre com traqueostomía por câncer \\ Haze Maria Carolia Risolia e Mendonçaํ, Keila Oliveira' ${ }^{1}$, Laís Reis Siqueira', \\ Maria Angélica Mendes ${ }^{1}$, Silvana Maria Coelho Leite Fava ${ }^{1}$, Eliza Maria Rezende Dázio ${ }^{1}$
}

\begin{abstract}
RESUMO
Objetivo: Conhecer a vivência do cuidador familiar de homem com traqueostomia por câncer. Métodos: Pesquisa qualitativa, aprovada sob parecer n 975.777, fundamentada no referencial da American Nursing Diagnoses Association, desenvolvida por meio de entrevistas e análise indutiva. Participaram do estudo sete cuidadores familiares de homens com traqueostomia por câncer, cadastrados em uma Unidade de Assistência de Alta Complexidade em Oncologia (UNACON). Resultados: Emergiram as categorias: tensão do papel de cuidador; processos familiares interrompidos; e papel dos profissionais de enfermagem no âmbito hospitalar e na atenção básica. Conclusão: A vivência do cuidador familiar está relacionada às mudanças de sua vida pessoal, à rotina diária e aos sentimentos desencadeados pela necessidade de assumir um novo papel. O conhecimento dessa realidade é essencial para o planejamento da assistência de enfermagem de qualidade e para a elaboração de políticas públicas que atendam às reais necessidades dessas pessoas.
\end{abstract}

DESCRITORES: Estomaterapia. Enfermagem. Traqueostomia. Cuidador.

\begin{abstract}
Objective: To know the experience of family caregivers of man with tracheostomy due to cancer. Methods: Qualitative research, approved under opinion No. 975.777, based on the reference by the American Nursing Diagnoses Association, developed through interviews and inductive analysis. Seven family caregivers of men with tracheostomy due to cancer, enrolled in a High Complexity Oncology Care Unit (UNACON), participated in the study. Results: The following categories emerged: tension of the role of caregiver; interrupted family processes; and role of nursing professionals in hospital and in primary care. Conclusion: The experience of the family caregiver is related to changes of his personal life, daily routine and feelings triggered by the need to take on a new role. The knowledge of this reality is essential for the planning of quality nursing care and for the elaboration of public policies that meet the real needs of these people.
\end{abstract}

DESCRIPTORS: Stomatherapy. Nursing. Tracheostomy. Caregiver.

\section{RESUMEN}

Objetivo: Conocer la experiencia del cuidador familiar de hombre con traqueostomía por cáncer. Métodos: Investigación cualitativa, aprobada bajo el dictamen № 975.777, fundamentada en el referencial de la American Nursing Diagnoses Association, desarrollada a través de entrevistas y análisis inductivo. En el estudio participaron siete cuidadores familiares de hombres con traqueostomía por cáncer, catastrados en una Unidad de Asistencia de Alta Complejidad en Oncología (UNACON). Resultados: Emergieron las categorías tensión del papel de cuidador; procesos familiares interrumpidos;

${ }^{1}$ Universidade Federal de Alfenas - Alfenas (MG), Brasil.

Endereço para correspondência: Universidade Federal de Alfenas - Rua Gabriel Monteiro Silva, 700 - Centro - CEP: $37130-001$ - Alfenas (MG), Brasil E-mail: haze_risolia@hotmail.com

Artigo recebido em: 11/10/2016 - Aceito para publicação em: 01/07/2017 
y papel de los profesionales de enfermería en el ámbito hospitalario y en la atención básica. Conclusión: La vivencia del cuidador familiar está relacionada con los cambios de su vida personal, la rutina diaria y los sentimientos desencadenados por la necesidad de asumir un nuevo papel. El conocimiento de esta realidad es esencial para la planificación de la asistencia de enfermería de calidad y para la elaboración de políticas públicas que atiendan a las necesidades de esas personas.

DESCRIPTORES: Estomaterapia. Enfermería. Traqueostomía. Cuidador.

\section{INTRODUÇÃO}

O câncer de cabeça e pescoço é considerado um sério problema de saúde pública e está entre os dez tipos de câncer mais frequentes no mundo ${ }^{1}$. Contribuem para o desenvolvimento dessa neoplasia a predisposição genética, a exposição à poluição de indústrias e ao tráfego, hábitos alimentares inadequados e a exposição a agentes carcinogênicos (principalmente extrínsecos, como álcool e tabaco) ${ }^{2}$.

O termo "câncer de cabeça e pescoço" é usado para descrever neoplasias do trato aerodigestivo superior. Constituem os sítios anatômicos desse grupo: cavidade oral, faringe, incluindo nasofaringe, hipofaringe, cavidade nasal, seios paranasais, laringe e glândulas anexas². O estadiamento da neoplasia determinará a opção terapêutica, sendo o tratamento cirúrgico o mais empregado, seguido da radioterapia, da quimioterapia e da imunoterapia. Nos tratamentos cirúrgicos do tipo laringectomias, mandibulectomias e glossectomias, a pessoa pode necessitar de tecnologias assistivas, como traqueostomia ou sonda nasogástrica. As repercussões do procedimento cirúrgico e de seus desdobramentos podem ocasionar comprometimentos funcionais ou limitações nas atividades de vida diária, representadas pela perda do movimento dos ombros, da voz, do sentido olfativo, dentre outras ${ }^{3}$.

A traqueostomia consiste em um procedimento cirúrgico caracterizado pela abertura da parede anterior da traqueia e pela construção do estoma, com sutura nas bordas da pele do pescoço, comunicando-a com o meio externo, para preservar a função respiratória. É indicada em casos de obstrução das vias aéreas, de acúmulo de secreção traqueal, de debilidade da musculatura respiratória ou, ainda, para prover uma via aérea estável na intubação traqueal prolongada ${ }^{4}$.

É importante ressaltar que, ao receber o diagnóstico de câncer, a pessoa pode sentir-se vulnerável, em decorrência do estigma que a doença representa na sociedade, pois é culturalmente entendida como sentença de morte, além da presença de um estoma, sendo este medo aflorado tanto nos períodos pré-operatório e pós-operatório quanto no processo de alta hospitalar. Diante dos medos, das incertezas e das dificuldades na comunicação apresentadas pelo paciente; diante dos questionamentos dos pacientes e de seus familiares quanto ao prognóstico, à forma de lidar com a cânula de traqueostomia, aos cuidados com a incisão cirúrgica, à forma de comunicação, à dieta, ao uso de medicações; e frente ao receio da alta hospitalar, percebe-se que o impacto do tratamento na vida do paciente e de seus familiares vai muito além da dimensão física ${ }^{5}$.

Nesse contexto, o tratamento cirúrgico exigirá suporte da equipe multidisciplinar e adaptação por parte do paciente e da família. Mesmo que esse tratamento seja uma oportunidade à manutenção da vida, a investigação e a reflexão sobre o universo da pessoa com câncer e traqueostomia levam o profissional de saúde a deparar-se com as diversas implicações dessa situação. Pode haver a necessidade de um familiar se tornar o cuidador principal, decorrente da dependência nas atividades de vida diária do indivíduo acometido, que muitas vezes necessita de cuidados integrais. Embora a vivência pertença exclusivamente à pessoa com câncer $\mathrm{e}$ traqueostomia, o planejamento da terapêutica com vistas à sua reabilitação interessa, também, aos familiares, ao familiar cuidador e à equipe de saúde que o assiste - principalmente ao enfermeiro.

Diante de nossas vivências na clínica cirúrgica, surgiram alguns questionamentos: Como é o dia a dia, as dificuldades e o convívio dos cuidadores familiares de pacientes homens?

Diante do exposto, este estudo teve como objetivos caracterizar o cuidador e conhecer a vivência do cuidador familiar de homem com traqueostomia por câncer.

\section{MÉTODO}

Trata-se de um estudo descritivo de abordagem qualitativa. Participaram do estudo sete cuidadores familiares de 
homens com traqueostomia por câncer. A coleta de dados foi realizada no período de março a maio de 2015, no contexto familiar de pessoas residentes no município-sede da Unidade de Assistência de Alta Complexidade em Oncologia (UNACON) e em cidades circunvizinhas, onde os moradores também são contemplados com o tratamento oncológico nessa unidade.

Os critérios de inclusão foram: pessoas de ambos os gêneros; maiores de 18 anos; com clara capacidade de comunicação e desejo de participarem do estudo; e cuidadores familiares de homens com diagnóstico médico de câncer de cabeça e pescoço ou de vias aéreas inferiores, cadastrados na UNACON de um hospital filantrópico de Minas Gerais, que tiveram como alternativa terapêutica a construção de uma traqueostomia.

Inicialmente, foi empregado um formulário semiestruturado composto por dados sociodemográficos visando à identificação dos participantes. Em seguida, iniciou-se a entrevista semiestruturada gravada em áudio, disparada pela seguinte questão aberta: "Conte-me do seu dia a dia de cuidador de homem com diagnóstico de câncer e com traqueostomia." O número de participantes esteve condicionado ao alcance do objetivo proposto neste estudo. Após a finalização da coleta de dados e a transcrição de cada entrevista, passou-se à análise dos dados, seguindo as seguintes etapas: ordenação e classificação dos dados, elaboração de narrativas e análise final ${ }^{6}$. Na primeira etapa, foram organizados os dados transcritos das entrevistas para se ter uma visão do todo. Na segunda etapa, esses dados foram classificados visando a identificar as ideias centrais e os principais pontos em comum entre elas. Em seguida, realizou-se a análise indutiva dos dados, integrando-os ao referencial teórico ${ }^{7}$.

O estudo foi aprovado pelo Comitê de Ética em Pesquisa (CEP) da Universidade Federal de Alfenas (UNIFAL), Minas Gerais, em cumprimento à Resolução no 466/2012, do Ministério da Saúde, que versa sobre pesquisa envolvendo seres humanos, sob o Protocolo no 975.777. Os participantes assinaram o Termo de Consentimento Livre e Esclarecido e, para preservar o anonimato, receberam nomes fictícios na confecção do artigo.

\section{RESULTADOS}

Participaram deste estudo sete pessoas, com predomínio do gênero feminino, na faixa etária entre 40 e 50 anos, católicas e com renda entre um e dois salários mínimos. Um dos cuidadores cursou o ensino médio, quatro cursaram o ensino fundamental e dois não frequentaram a escola; ademais, um era lavrador e quatro dedicavam-se integralmente ao familiar adoecido.

$\mathrm{Na}$ análise dos dados fundamentada no referencial teórico proposto ${ }^{7}$, foram construídas três categorias: tensão do papel de cuidador; processos familiares interrompidos; e papel dos profissionais de enfermagem no âmbito hospitalar e na atenção básica. que serão apresentadas a seguir.

A categoria "tensão do papel de cuidador" ficou evidente nos seguintes depoimentos:

Fico cansada, sem ânimo e muito brava com as crianças, sabe? Perco a paciência rápido e acabo gritando o dia todo. Tenho medo de mexer na traqueostomia até hoje, mas tenho que fazer mesmo e ninguém mais tem coragem. É difícil, tenho muito medo e às vezes penso que não vou aguentar, mas ele não tem ninguém além de mim que tem paciência com ele. Ele nunca aceitou ajuda, acho que é difícil pra ele. (Cora)

Depois da quimio, ele disse que começava um fogo assim no estômago dele que ia subindo pra cima, e ele dizia "vou morrer, vou morrer, vou morrer", e eu não tinha jeito de ficar em casa. Foi difícil, eu tinha que trabalhar e ele não conseguia ficar sozinho. (Adélia)

Só que eu fico de olho nele o dia inteirinho. Às vezes eu acordo de noite [...] e olho ele, mas cansa, ele está muito magro, e eu tenho bico de papagaio nas costas. É muito triste isso pra mim, a gente não foi feito pra perder filho, isso está ao contrário. (Virgílio)

Olha, no começo, e até mesmo agora, está sendo muito difícil [...] agora eu fico muito cansada, e eu não posso deixar o marido sozinho $[. .$.$] porque não sei quando ele poderá$ ir embora. (Inês)

Para enfrentar a condição imposta, os cuidadores buscam recolocações, novas adaptações - tanto na vida pessoal como na profissional - e suporte na espiritualidade. "No começo foi mais difícil porque quem trabalhava era o marido [familiar traqueostomizado] e eu ficava aqui cuidando da casa e dos meninos, só que agora melhorou [...] é Deus que me dá força pra continuar tudo isso", alegou Inês em sua entrevista. 
A categoria "processos familiares interrompidos" pode ser percebida pelas dificuldades de aceitação da doença por parte do paciente, o que pode gerar desequilíbrio nas relações familiares e levar o adoecido a uma relação de hostilidade com o cuidador, como representado nos seguintes depoimentos:

Ficou muito irritado e brigava à toa com a gente. Está muito difícil pra mim, e não está sendo fácil, ele anda muito nervoso, muito estressado. Quando a gente fala pra ele que ele está muito nervoso, ele fala pra gente: - é porque vocês não têm isso que eu tenho, vocês não sabem o que eu estou passando. (Adélia)

Eu acho que é mais difícil pra ele do que pra mim, porque ele não gostava que eu trabalhasse fora e agora eu tenho que fazer faxina, e ele está encostado. Ele já falou pra mim que quem tinha que cuidar e trazer dinheiro pra casa era ele e não a mulher dele. (Inês)

Adélia demonstra uma adaptação negativa diante da situação vivenciada, exteriorizando sintomas depressivos.

Eu fiquei pior do que ele [familiar com traqueostomia], a psicóloga lá da oncologia falou pra mim: - ele está melhor do que eu, eu fiquei doente, eu emagreci uns quatro quilos, eu fiquei... nossa, na base de calmantes. Parece que eu estou tipo assim... depressiva, eu não tenho vontade de sair, de passear, de ir na igreja, nem nada. Relação sexual faz muito tempo que a gente não tem, uns quatro, cinco anos. Está fazendo falta, mas faz mais falta pra ele do que pra mim, porque o psicológico meu está muito ruim e com a cabeça ruim. Você não tem cabeça pra isso? Eu ainda tomo meu calmante. (Adélia)

Pode-se observar a dedicação de Dante e de Inês ao assumirem o papel de cuidador, o que os aproximou ainda mais de seus familiares cuidados: "Oh, melhorou bastante o nosso relacionamento, muito! A gente ficou mais amigo e mais irmão. Foi sossegado porque eu não tenho nojo das coisas, se for meio fraco não consegue conviver com isso" (Dante); "Os meninos ficaram apegados ao pai, a gente aqui é unido [...]. O marido ficou manso. A doença mudou muito a gente" (Inês).

A categoria "papel dos profissionais de enfermagem no âmbito hospitalar e na atenção básica” pode ser constatada no setor terciário, no qual as informações são geralmente obtidas no momento da alta hospitalar - período em que as pessoas encontram-se ansiosas para o retorno ao lar. Entretanto, parece que essas informações não foram devidamente compreendidas pelo cuidador:

Recebi orientação da enfermeira lá do hospital, ela me chamou, acho que eu fiquei mais ou menos uma hora com ela no quarto, era difícil entender o que ela falava. Ele [familiar com traqueostomia] já estava de alta, aí lá no hospital a equipe de enfermagem usava o sugador e em casa não iria usar sugador, aí parecia que em casa ele tinha falta de ar, então eu peguei o aspirador e levei pra ele pra ver se melhorava. (Cecília)

E a necessidade de acompanhamento no âmbito domiciliar parece não ter sido atendida: “[...] Quem falou foi a enfermeira do PSF [Programa de Saúde da Família] que mandou eu limpar o caninho sempre, mas não vou lembrar as coisas que ela falou não [...]. O médico e enfermeira já vieram aqui em casa algumas vezes [...]” (Cora); "Ninguém me explicou, ninguém sabe? Nem aqui a mulher que era chefe do PSF, nem sei falar aquilo, não quis colocar a mão, aqui no pronto socorro também não quis colocar a mão [...]” (Adélia).

\section{DISCUSSÃO}

Esta pesquisa voltou-se para a atenção ao cuidador que possui um importante papel para a sua família, para a sociedade e até mesmo para o Sistema Único de Saúde (SUS), pois acaba por assumir grande parcela do cuidado das pessoas acometidas pelo câncer e que possuem traqueostomia. Neste estudo, há o predomínio de cuidadores do gênero feminino, o que corrobora com os dados encontrados na literatura: historicamente, a figura feminina é eleita para o cuidado, e a atividade de cuidar é uma atribuição natural da mulher ${ }^{8}$. Cuidadores do gênero masculino não são muito comuns - neste estudo, eles são representados por um pai e um irmão, que acabaram por assumir o cuidado devido à ausência de uma figura feminina. A literatura mostra os cuidadores do gênero masculino como um pequeno grupo à parte, com suas próprias necessidades, preocupações e desafios ${ }^{8}$.

Em relação ao grau de escolaridade, apenas um cuidador afirmou ter ensino médio completo. A escolaridade 
predominantemente baixa pode ter contribuído para a baixa renda e para que o próprio familiar se tornasse o cuidador principal, pois a inserção no mercado de trabalho para aqueles com baixa escolaridade é mais difícil. No entanto, em decorrência do aumento de gastos devido às despesas com o adoecimento do familiar, muitas vezes os cuidadores são obrigados a conseguir um trabalho informal e árduo, pois precisam aumentar ou até mesmo assumir o papel de provedor da família9 .

No que diz respeito ao estado civil, há um predomínio de participantes casados, o que corrobora para dificultar a prestação dos cuidados, pois além dos afazeres domésticos, os cuidadores precisam dividir seu tempo entre o familiar dependente e os outros familiares, ou até mesmo com um emprego para ajudar nas despesas, o que pode gerar sobrecarga de responsabilidades ${ }^{10}$. Referente ao tempo dedicado ao cuidado do familiar adoecido, quatro participantes relataram dedicar-se em tempo integral; os outros três, mais de quatro horas por dia. A nosso ver, a dedicação em tempo integral contribui para alterações nas diversas dimensões $\mathrm{da}$ vida do cuidador - físicas, psicossociais e financeiras o que pode gerar tensão.

\section{Tensão do papel de cuidador}

Além do comprometimento das diferentes dimensões da vida, assumir o papel de cuidador implica ter que lidar com a gravidade e a imprevisibilidade do curso da doença, com a sobrecarga e a complexidade das atividades, e dedicar tempo ao cuidado, o que gera um sentimento de exaustão pela mudança na rotina diária ${ }^{11,12}$.

Soma-se a isso o fato de que a progressão da doença tende a enfraquecer as pessoas, aumentando a sua dependência, tornando cada vez mais prolongada e estressante a prestação dos cuidados, o que pode gerar sentimentos negativos, como o mal-estar físico e emocional ${ }^{13}$.

Em decorrência de fatores que, de uma forma ou de outra, contribuem para a tensão do papel de cuidador, sobrevêm recolocações e novas adaptações tanto na vida pessoal como na profissional. É comum os cuidadores desenvolverem uma capacidade de adaptação positiva às situações de doença do ente querido, sendo que a resolução do problema e a adaptação também incluem mudanças e tempo ${ }^{14,15}$.

O sofrimento dos cuidadores é minimizado por meio da espiritualidade, o que pode motivar aspectos subjetivos, como o bem-estar, favorecendo o suporte social e a interação com um Ser Superior. Deus é fonte de conforto e de orientação, sendo que essa relação pode fornecer sentido e novos significados para circunstâncias problemáticas ${ }^{15,16}$.

Os cuidadores que possuem crenças religiosas apresentam um enfrentamento com satisfação e esperança. Os depoimentos dos cuidadores mostraram que eles sofrem junto com os familiares adoecidos, e a existência da fé e da espiritualidade funciona como refúgio e sustentação em todos os momentos, principalmente nos de crise, auxiliando-os a enfrentar essa fase ${ }^{17}$.

\section{Processos familiares interrompidos}

Frente ao adoecimento de um membro da família por câncer e ao tratamento que resulta em traqueostomia, os processos familiares estão sujeitos às mudanças em seus relacionamentos e em sua dinâmica. Essas estão relacionadas com alterações nas condições socioeconômicas; com a geração de conflitos entre paciente e cuidador ou a prontidão para melhorar o enfrentamento familiar com dedicação ao assumir o papel de cuidador; e com a maior aproximação entre eles. A situação pode ser agravada pelo nível de desconhecimento sobre a doença e pelo baixo grau de escolaridade, que podem dificultar a compreensão do processo de adoecimento e da missão do cuidador. Destaca-se a inversão de papéis: neste estudo, uma mulher assume a função de provedora da casa e uma pessoa idosa cuida de um jovem ${ }^{13,14}$.

Os conflitos gerados entre o familiar adoecido e o cuidador podem ser decorrentes de uma estrutura familiar na qual os membros possuem dificuldades para absorver todo o contexto que a situação de adoecimento lhes impõe. Ademais, o adoecimento de um membro da família pode acometer outros, em especial o cuidador principal, provocando estresse, cansaço, irritabilidade, negação do papel e insatisfação consigo mesmo, podendo deixá-los deprimidos. Ao mesmo tempo, os conflitos também são sentidos pelos pacientes, que sofrem com a inversão de papéis, sentem insatisfação com seu estado de saúde e são prejudicados pela falta de conhecimento sobre a doença ${ }^{14}$.

Ainda sobre a falta de aceitação por parte da pessoa adoecida, vale destacar o sofrimento causado pela inversão de papéis: quem antes era o principal apoio familiar agora passa a conviver com a sensação de estar incomodando. Questões de masculinidade estão presentes na nossa cultura; o homem é o mantenedor do lar e a mulher, a cuidadora - para os homens, a responsabilidade pelo sustento do lar tem papel de destaque $\mathrm{e}^{10-18}$. 
A experiência e a vivência do cuidador são únicas, e estão relacionadas às mudanças e aos sentimentos desencadeados pelo fato de ter que se adaptar e assumir um novo papel. A experiência de prestar o cuidado faz com que o cuidador passe por um processo adaptativo, o que pode exteriorizá-lo tanto de maneira positiva quanto negativa, produzindo naturalmente desdobramentos em seu estado físico e emocional.

\section{Papel dos profissionais de enfermagem no âmbito hospitalar e na atenção básica}

O apoio da equipe multiprofissional de saúde, principalmente do enfermeiro, contribui com o cuidador nesse intenso processo de cuidar, uma vez que tende a oferecer orientações e suporte necessários para minimizar os efeitos do adoecimento. Quando as orientações não são efetivas, pode haver sobrecarga física, emocional e econômica do cuidador ${ }^{10}$. É premente que os profissionais de saúde levem em consideração o grau de escolaridade do cuidador, pois a baixa escolaridade pode contribuir para o insucesso da aprendizagem e ampliar a insegurança.

$\mathrm{Na}$ maioria das vezes, no âmbito hospitalar, as orientações são prestadas de maneira informal, por meio de uma comunicação verbal repleta de termos técnicos, realizada no momento da alta hospitalar. Isso dificulta a compreensão, a apreensão dos saberes, e nem sempre o cuidador tem a oportunidade de revisar as ações ou até mesmo de efetuá-las diante do profissional de enfermagem $^{14,15-19}$. Os participantes deste estudo relataram dificuldades e insegurança no exercício do cuidado perante a situação de um familiar que necessita de cuidados complexos. Contribuem para essas dificuldades o sentimento de medo e a falta de familiaridade com recursos da tecnologia assistiva.

\section{CONSIDERAÇÕES FINAIS}

A vivência do cuidador familiar é única, sendo relacionada à mudança em sua vida pessoal, à rotina diária e aos sentimentos desencadeados pela necessidade de assumir um novo papel.É essencial que o profissional de saúde, especialmente o enfermeiro, compreenda os desdobramentos do adoecimento de uma pessoa com câncer e traqueostomia na família, a fim de oferecer ao cuidador o suporte necessário, pois cada cuidador deve ser acolhido em suas necessidades, comportamentos, sentimentos e nos significados que atribuem para essa vivência.

Apesar da demanda de relatos sobre as experiências e as vivências de cuidadores, foi constatada a escassez de estudos sobre cuidadores de pessoas com câncer e traqueostomia.

O conhecimento aprofundado de quem executa esse papel é essencial para a elaboração do planejamento da assistência de enfermagem de qualidade e eficaz, com vistas às necessidades dos cuidadores e também para nortear a elaboração de políticas públicas que atendam às reais necessidades dessas pessoas, uma vez que o câncer de cabeça e pescoço é considerado um problema de saúde pública, e a cada dia diversas pessoas são submetidas à traqueostomia.

Desenvolver este estudo nos fez refletir sobre o importante papel do enfermeiro na equipe multidisciplinar e sobre os desdobramentos do adoecimento de uma pessoa com câncer e traqueostomia na família, o que nos tornou mais humanos e comprometidos com a realidade social.

\section{REFERÊNCIAS}

1. Brasil. Instituto Nacional de Câncer José Alencar Gomes da Silva. Estimativa 2014: incidência de câncer no Brasil [Internet]. Rio de Janeiro: Inca; 2014[citado em abr. 2015]. Disponível em: http://www.inca.gov.br/bvscontrolecancer/ publicacoes/Estimativa_2014.pdf

2. Colombo J, Rahal P. Alterações genéticas em câncer de cabeça e pescoço. Rev Bras Cancerol [Internet]. 2009[citado em abr. 2015];55(2):165-74. Disponível em: http://www. inca.gov.br/rbc/n_55/v02/pdf/11_revisao_literatura2.pdf

3. Mostardeiro SCTS, Pedro ENR. O cuidado de enfermagem em situações de alteração da imagem facial. Rev Gaúcha Enferm. 2011 Jun;32(2):294-301.
4. Smeltzer SC, Hinkle JL, Bare BG, Cheever KH. Brunner e Suddarth: tratado de enfermagem médico-cirúrgica. $12^{\mathrm{a}}$ ed. Rio de Janeiro: Guanabara Koogan; 2011.

5. Santos GLJ, Lima MADS, Klock P, Erdmann AL. Conceptions of Nurses on Management of Care in an Emergency Department Descriptive Exploratory Study Online Brazilian Journal of Nursing. Online Braz J Nurs [Internet]. 2012 Abril[citado em jun. 2015];11(1):101-12. Disponível em: http://www.objnursing.uff.br/index.php/nursing/article/ view/3580/pdf

6. Minayo MCS, Deslandes SF, Gomes R. Pesquisa Social: teoria, método e criatividade. Rio de Janeiro: Vozes; 2010. 
7. Herdmann TH, editor. Diagnósticos de Enfermagem da NANDA-I: definições e classificação - 2012-2014. Porto Alegre: Artmed; 2013.

8. Neumann SMF, Dias CMSB. Doença de Alzheimer: o que muda na vida do familiar cuidador? Rev Psicol Saúde [Internet]. 2013[citado em jun. 2015];5(1):10-7. Disponível em: http:// pepsic.bvsalud.org/pdf/rpsaude/v5n1/v5n1a03.pdf

9. Lopez V, Copp G, Molassiotis A. Male caregivers of patients with breast and gynecologic cancer: experiences from caring for their spouses and partners. Cancer Nursing [Internet]. 2012[citado em jun. 2015];35(6):402-10. Disponível em: http://www.ncbi.nlm.nih.gov/pubmed/22067685

10. Souza ICP, Silva AG, Quirino ACS, Neves MS, Moreira LR. Perfil de pacientes dependentes hospitalizados e cuidadores familiares: conhecimento e preparo para as práticas do cuidado domiciliar. Rev Min Enferm [Internet]. 2014 Jan/ Mar[citado em jun. 2015];18(1):173-80. Disponível em: http://www.dx.doi.org/10.5935/1415-2762.20140013

11. Oliveira WT, Benedetti GMS, Marchi JA, Cassarotti MS, Wakiuchi J, Sales CA. Events that intensify and reduce stress in families of patients with cancer: an integrative review. Rev Min Enferm [Internet].2013 Jul-Set [citado em jun. 2015];17(3):713-19. Disponível em: www.reme.org.br/ exportar-pdf/683/en_v17n3a17.pdf

12. Ralph SS, Taylor CM. Manual de Diagnósticos de Enfermagem. $7^{\mathrm{a} e d .}$ Rio de Janeiro: Guanabara Koogan; 2009.

13. Nardi EFR, Sawada NO, Santos JLF. The association between the functional incapacity of the older adult the family caregivers burden. Rev Latino-Am Enferm [Internet]. 2013 Set/Out[citado em set. 2015];21(5):[8 telas]. Disponível em: http://www.scielo. br/pdf/rlae/v21 n5/pt_0104-1169-rlae-21-05-1096.pdf
14. Oliveira AEL, Campos AER. Alterações Cotidianas Vivenciadas pelos Familiares Cuidadores de Pacientes Oncológicos de um Hospital Filantrópico de Salvador-BA. UNOPAR Cient Ciênc Biol Saúde [Internet]. 2014[citado em set. 2015];16(3):1759. Disponível em: http://www.pgss.com.br/revistacientifica/ index.php/biologicas/article/view/1331

15. Loerzel VW, Crosby WW, Reising E, Sole ML. Developing the tracheostomy care anxiety relief through education and support (T-CARES) Program. Clin J Oncol Nurs [Internet]. 2014 Out[citado em set. 2015];18(5):522-7. Disponível em: https:// cjon.ons.org/sites/default/files/L58624127LOQH251_first.pdf

16. Moreira NS, Sousa CS, Poveda VB, Turrini RNT. Autoestima dos cuidadores de doentes oncológicos com capacidade funcional reduzida. Esc Anna Nery [Internet]. 2015 AbrJun[citado em jan. 2016];19(2):322-31. Disponível em: http:// www.scielo.br/scielo.php?script=sci_arttext\&pid=S141481452015000200316\&lng=es\&nrm=iso\&tlng=es

17. Geronasso MCH, Coelho D. A influência da religiosidade/ espiritualidade na qualidade de vida das pessoas com câncer. Saúde Meio Ambiente [Internet]. 2012 Jun[citado em jan. 2016];1(1):173-87. Disponível em: http://www. periodicos.unc.br/index.php/sma/article/view/227/270

18. Lamino DA, Turrini RNT, Kolcaba K. Cancer patients caregivers comfort. Rev Esc Enferm USP [Internet]. 2014[citado em jan. 2016];48(2):278-84. Disponível em: http://dx.doi. org/10.1590/S0080-623420140000200012

19. Valdes AG, Kamada I, Cristo RC, Costa SB, Faustino AM. Experiências de Crianças com Estomias: Estudo Qualitativo. Estima [Internet]. 2010 Jul-Set[citado em mar. 2016];8(3). Disponível em: https://www.revistaestima.com.br/index. php/estima/article/view/60 